$t i<1.1$ (Spring 2012)

\title{
Calligrammes...
}

\section{Alyssa Bakker}

« Pays imaginaire »

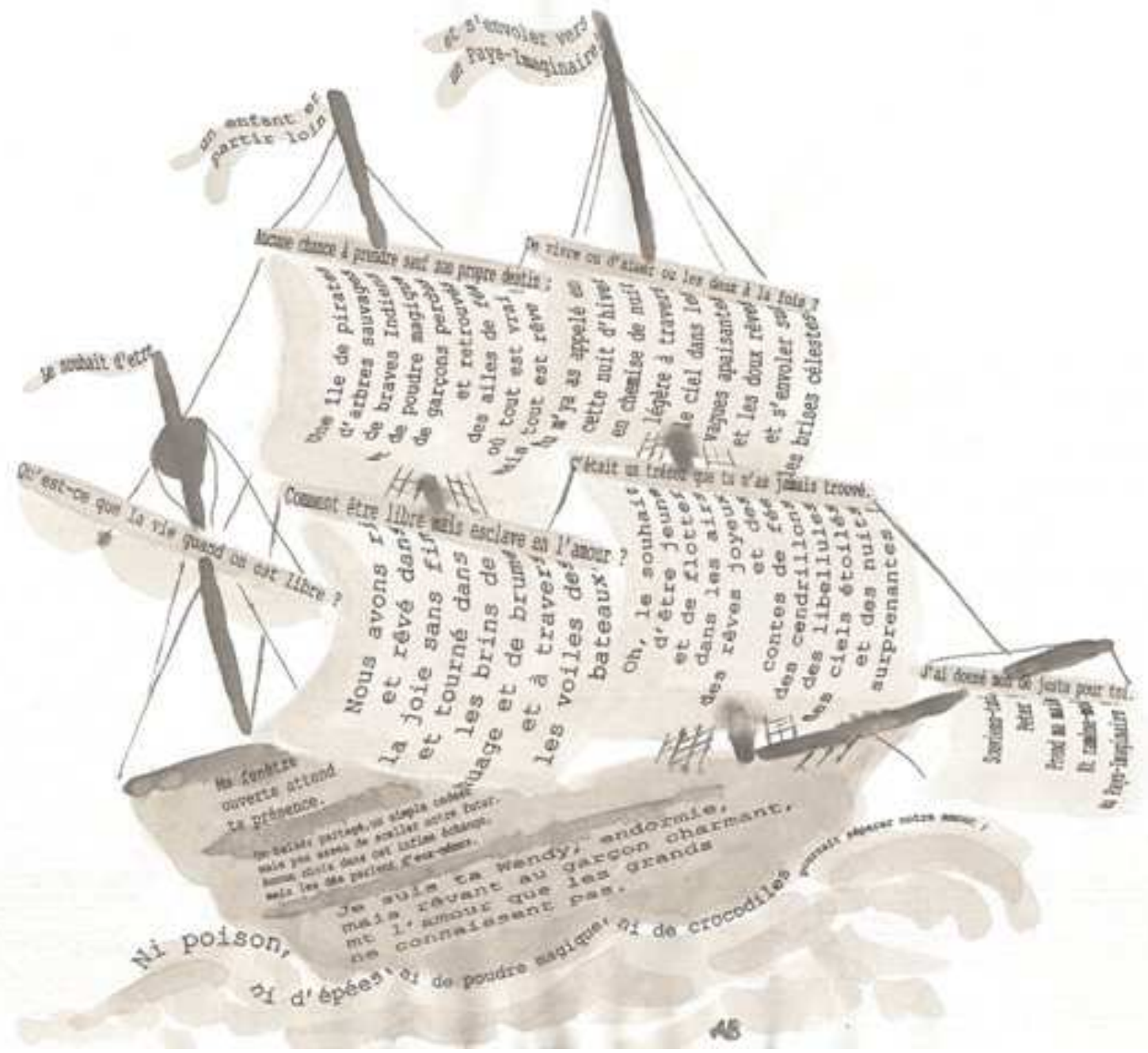


«Compotier avec fruits, violon et verre »
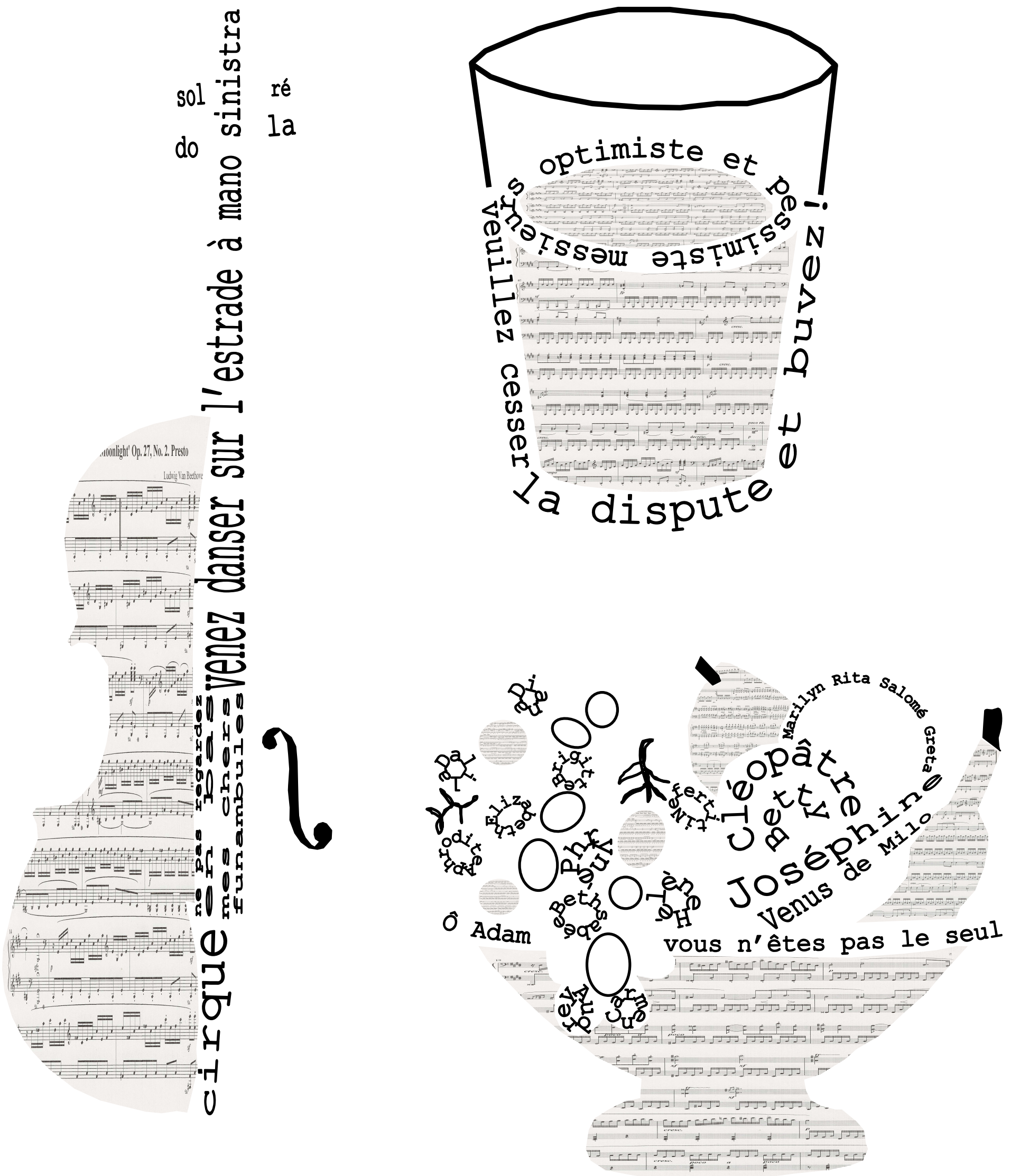
$t i<1.1$ (Spring 2012)

Josée Plouffe

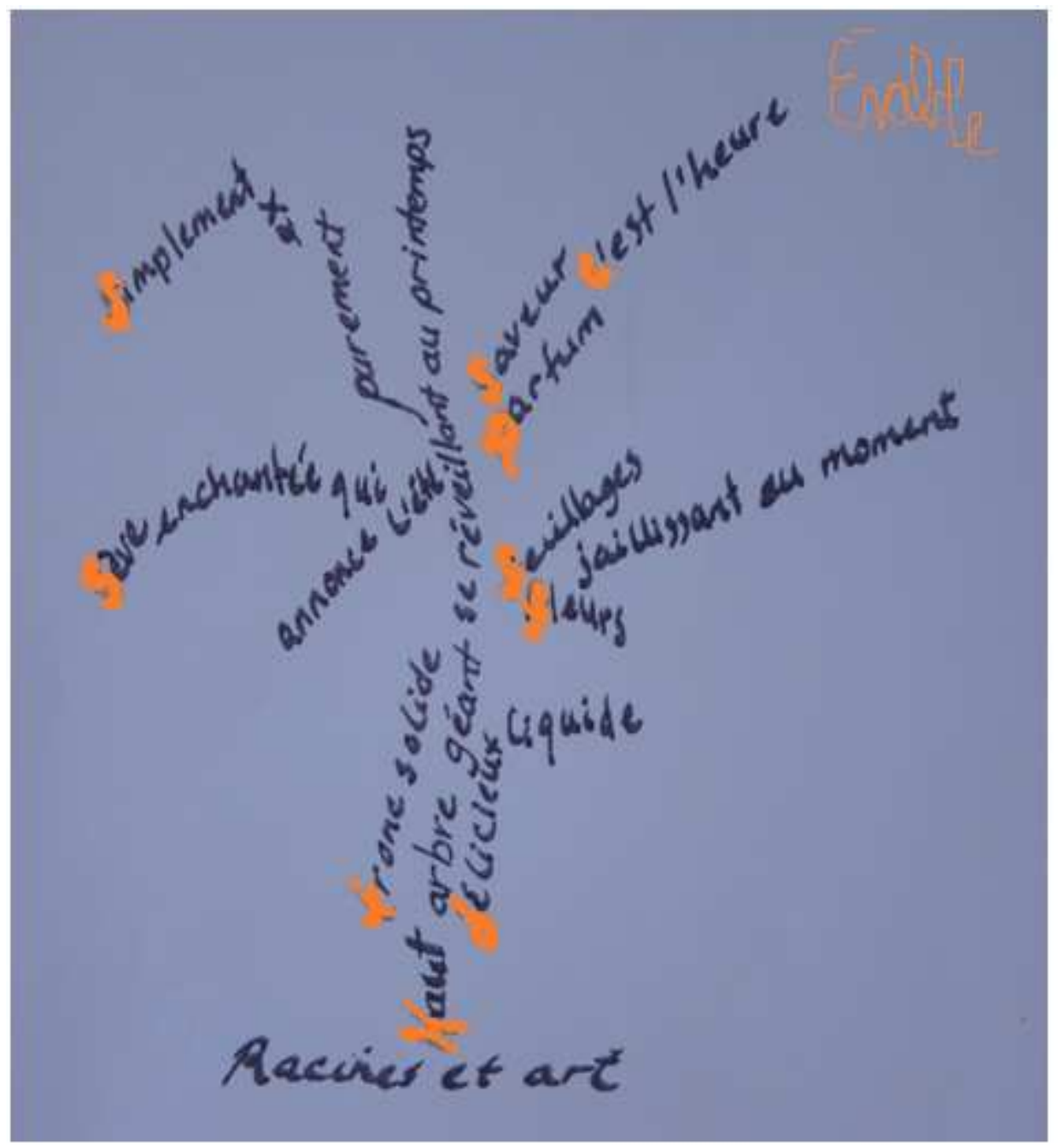


$t i<1.1$ (Spring 2012)

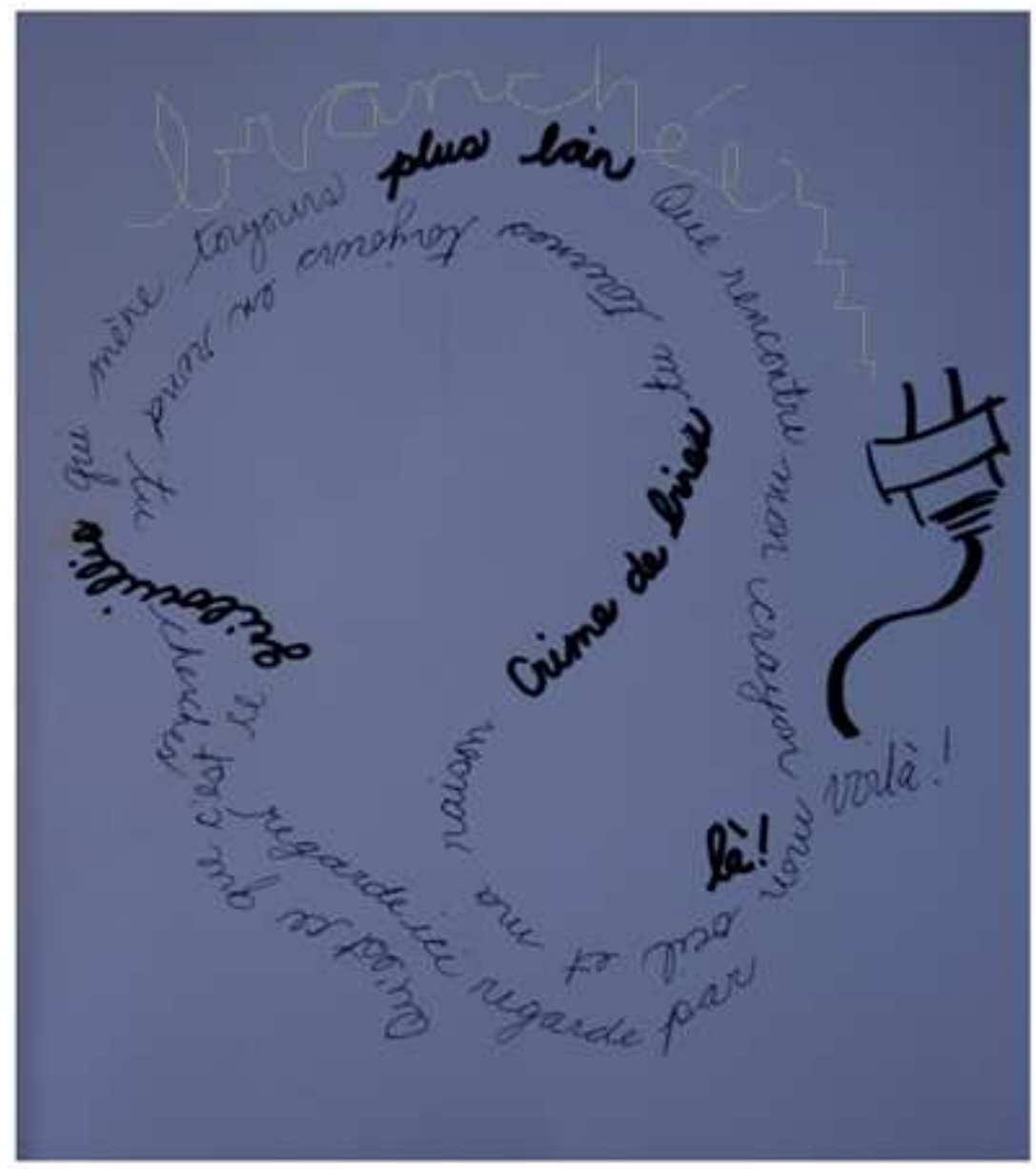




\section{diro of tovill}

4 Boyour chose comment ca yout? Voins f to 3

Tu Salmande pis ses choquins?

- Parfait choo driole histone et lan

- gue sielle metutrours llleme

- cherchesi tu eftaces essuietes

S larmes c'est citile Rire ox pleura

Clest inutile. Si tu portes ta salas $\$$

S Pette, ette, elle à bretelles. Viens

- Sarie un tom grorielle toesup ne

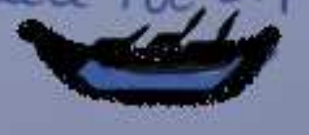


$t i<1.1$ (Spring 2012)

\section{Tess Lofthouse}

«Lordinateur, le clavier et la souris»

imaginer l'illusion imaginer l'impression instante interpréter les intérêts interpréter les indices.

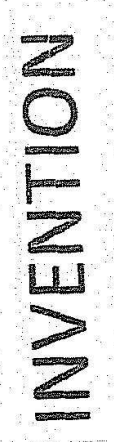

LOFTHOUSE

Inc.

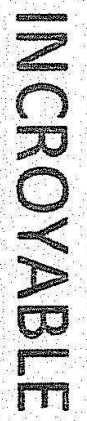

j'imprime l'imposteur idéal et immorte! instrument inanimé imitatrice incessant

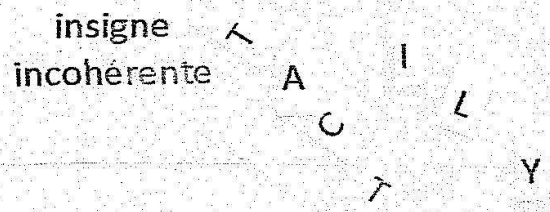

A

A

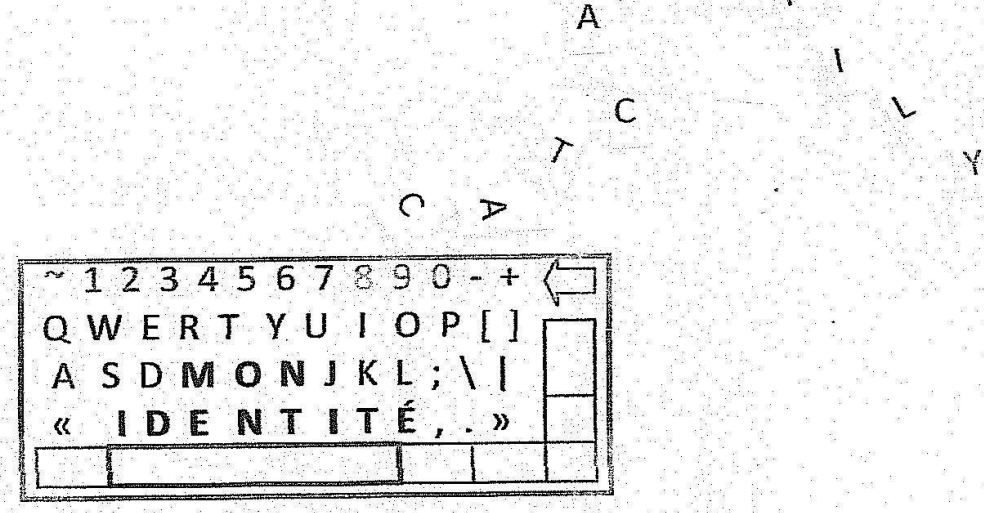

A

L

$Y$

c 
$t i<1.1$ (Spring 2012)

Vanessa Coutu

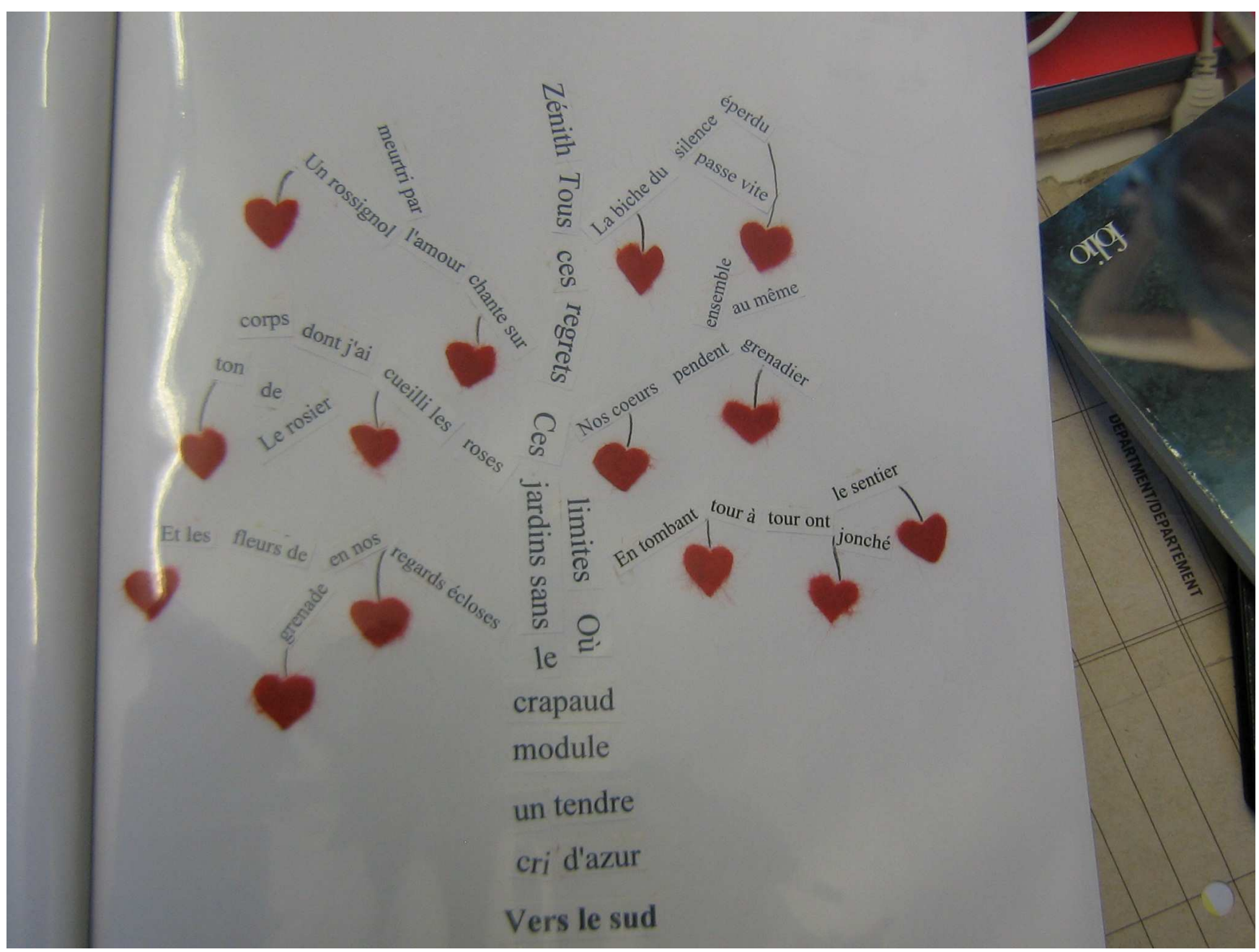




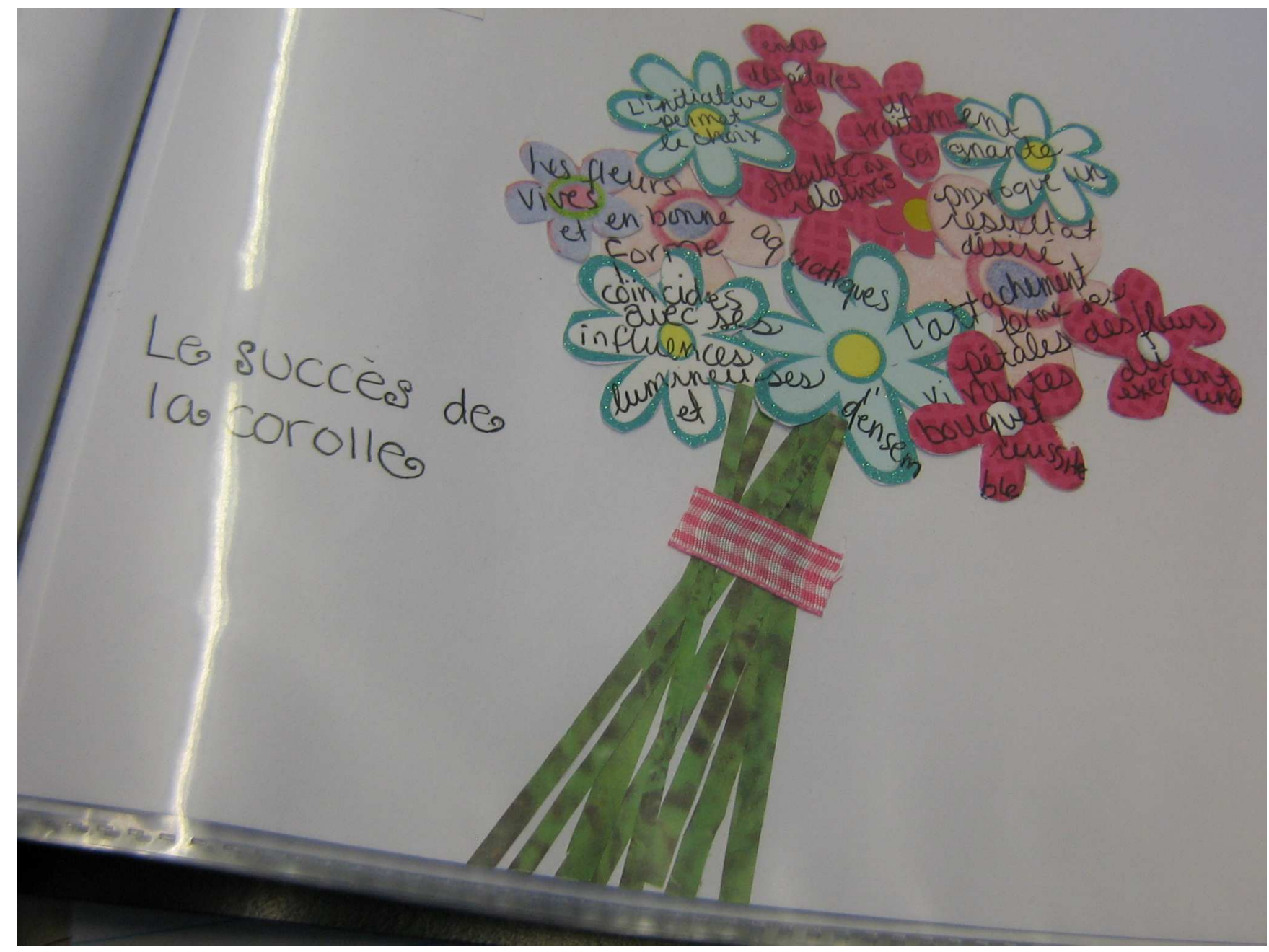




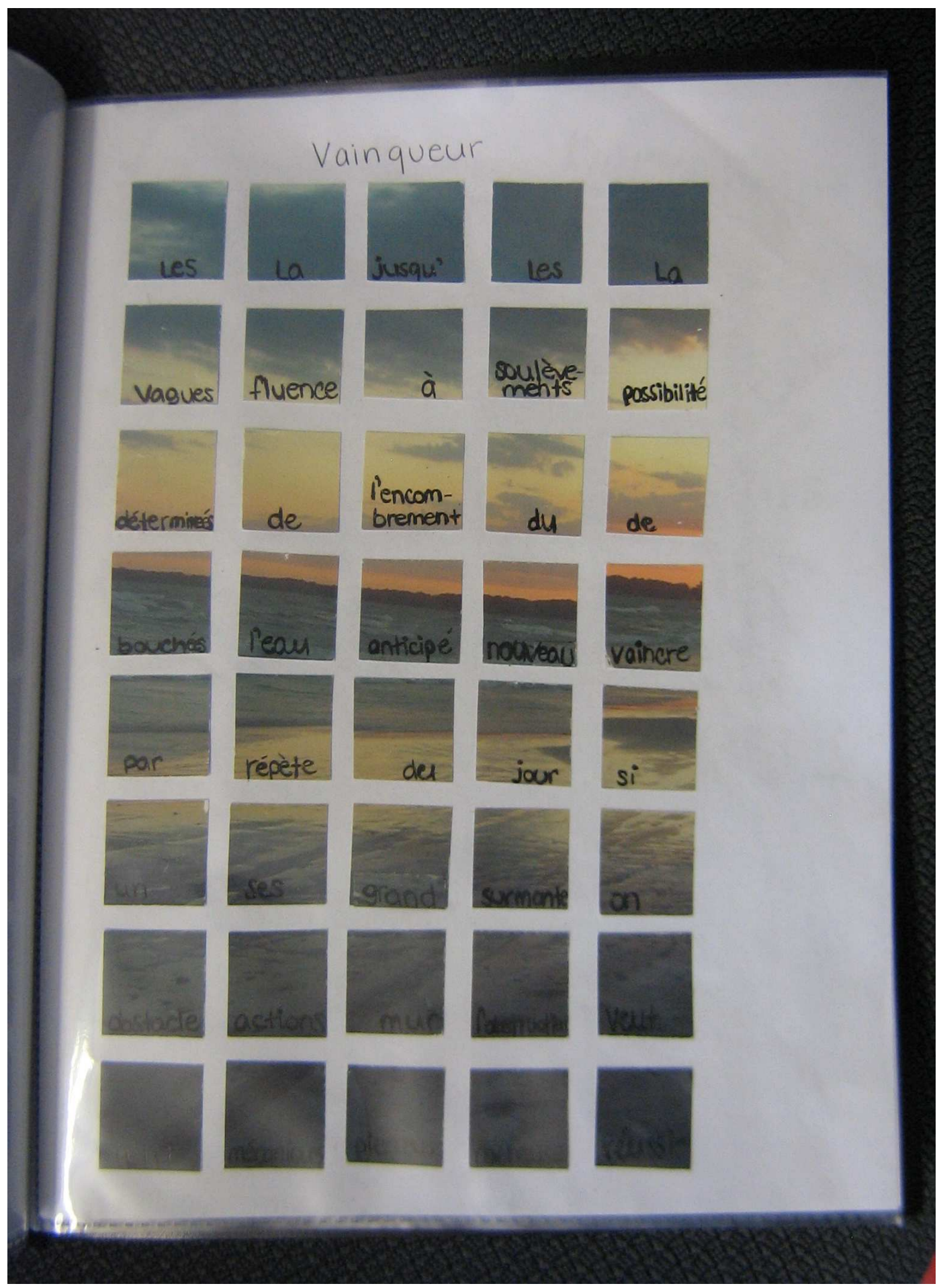




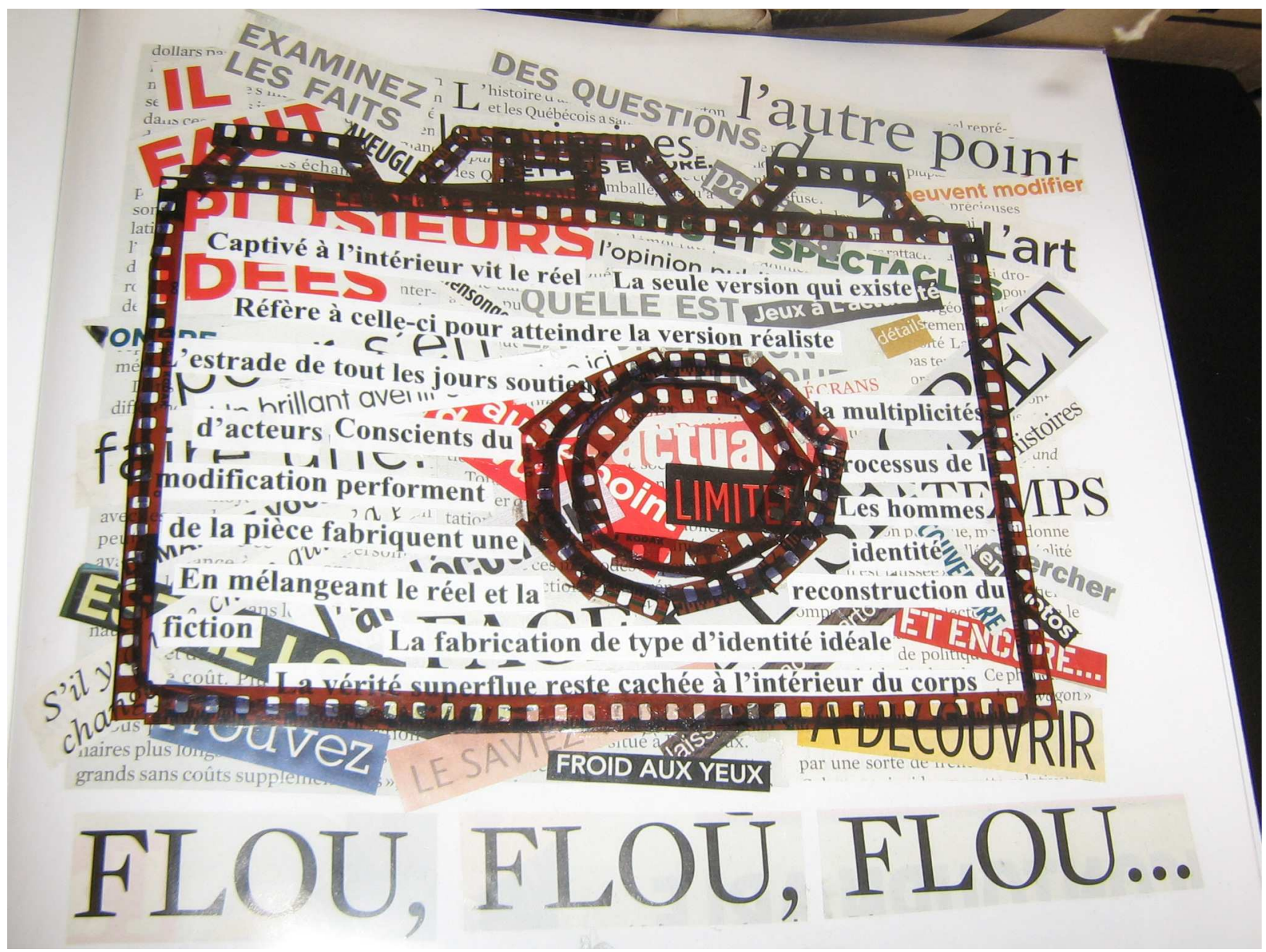


$t i<1.1$ (Spring 2012)

\section{Layal Aboukors}

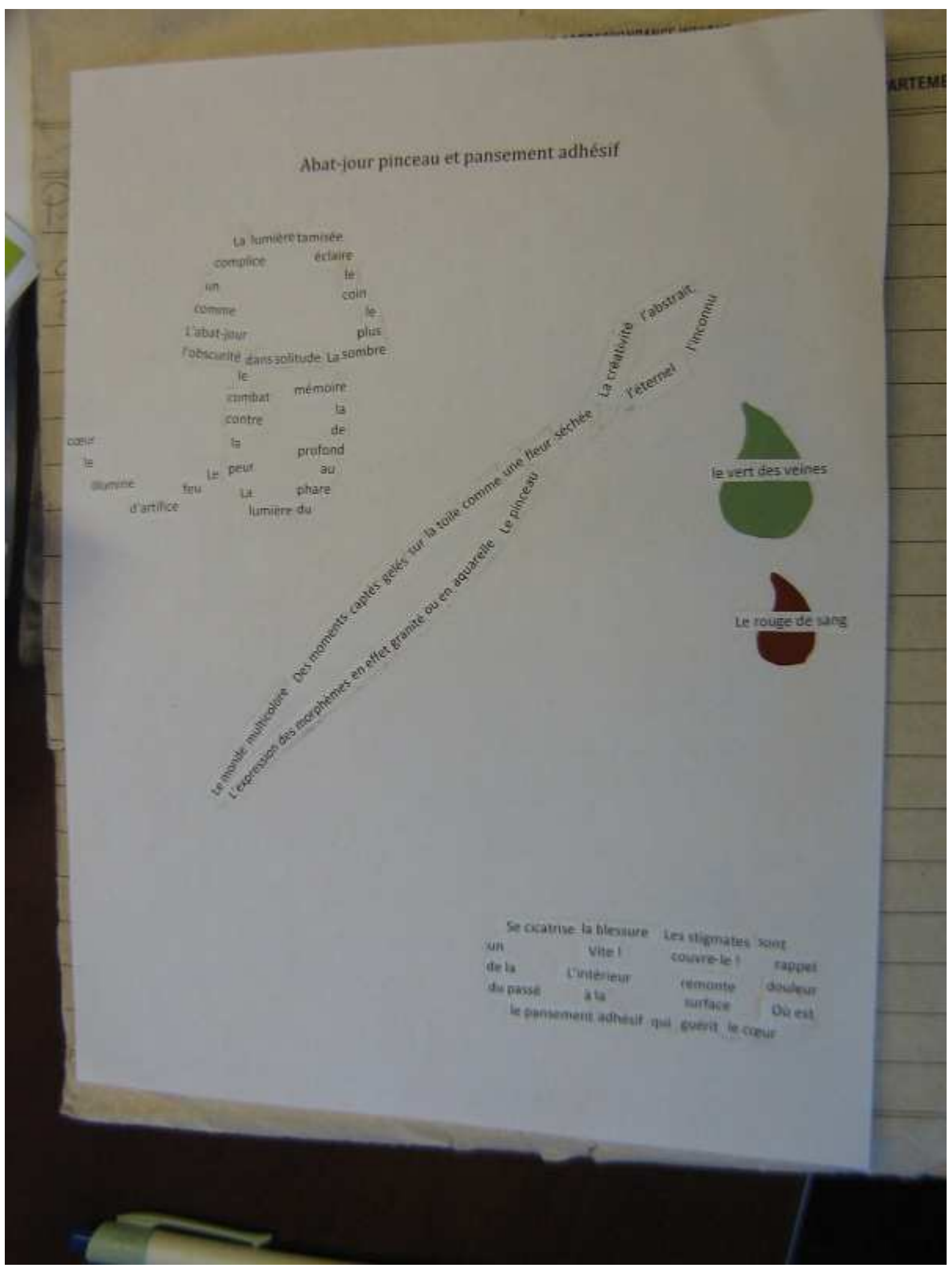




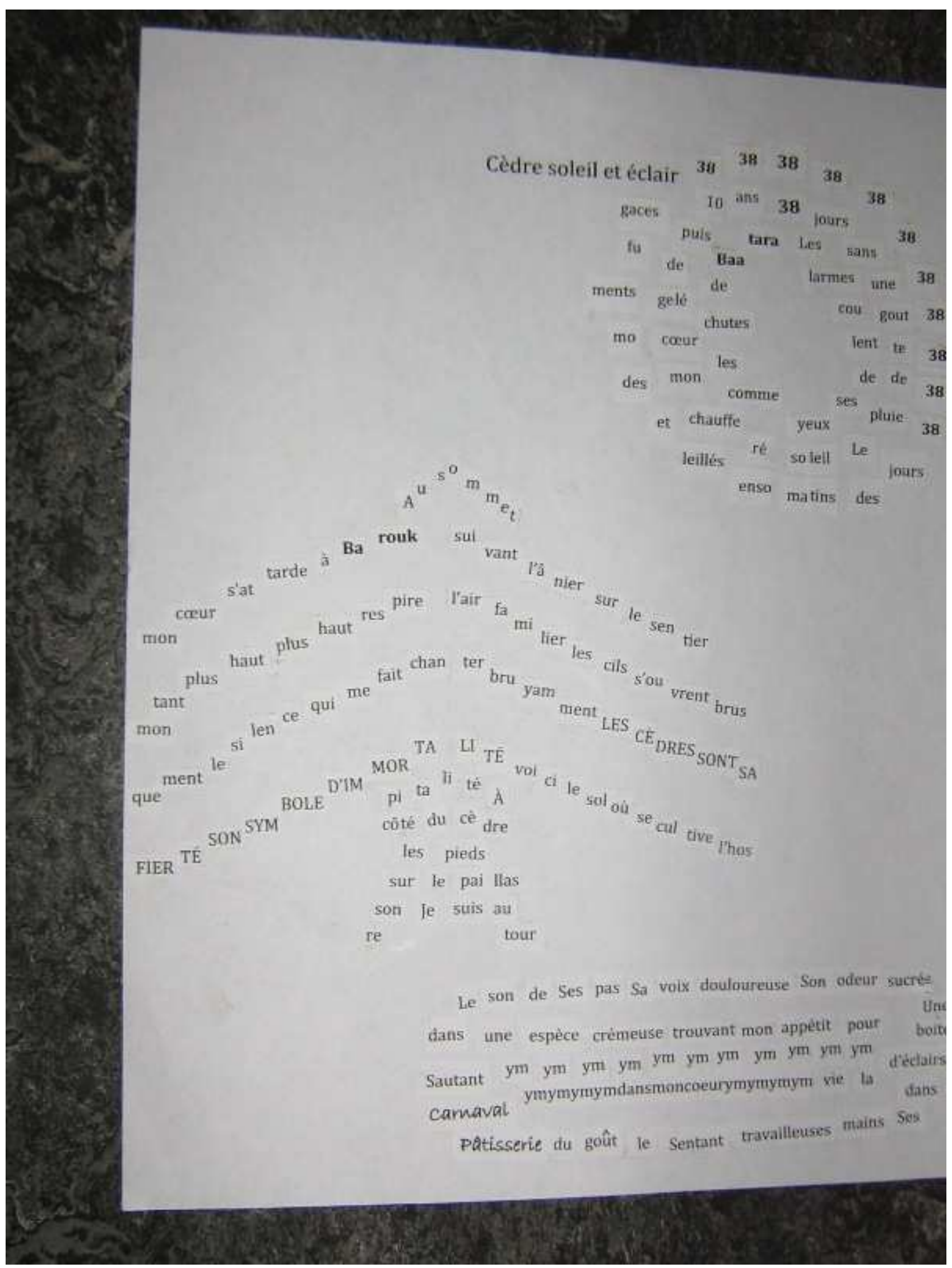


$t i<1.1$ (Spring 2012)

77

Catherine Parayre

« Marche Soulier »

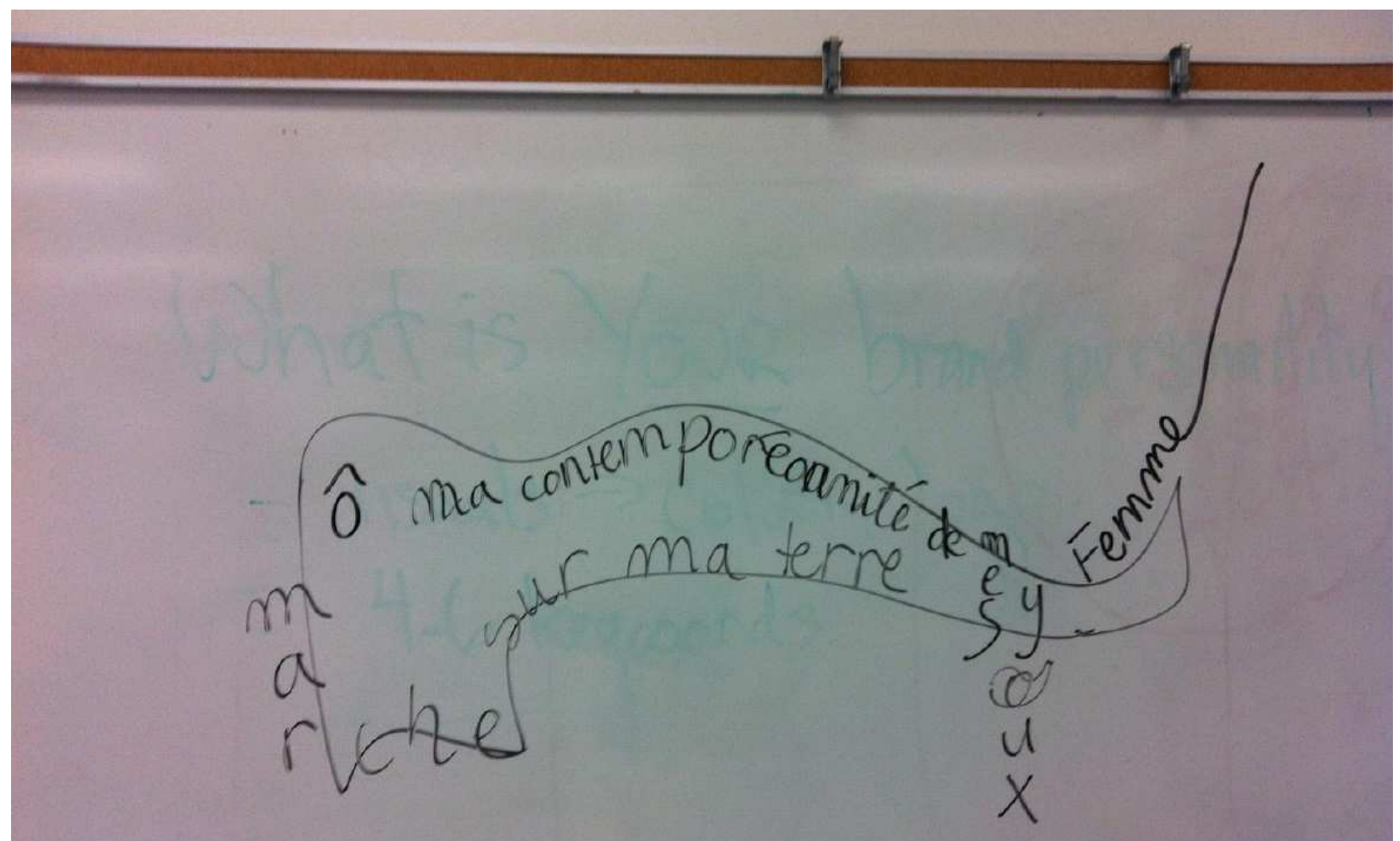




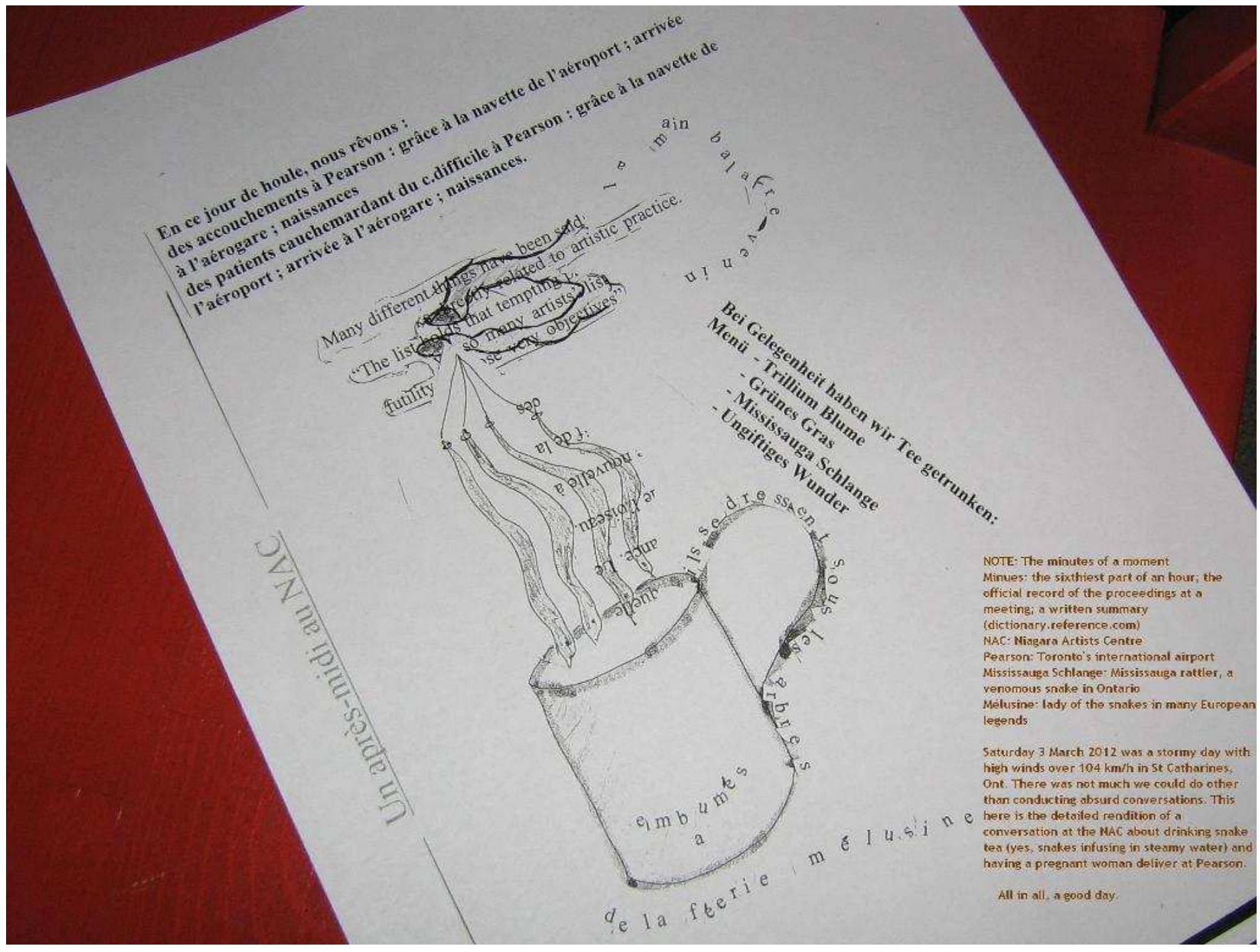

NOTE: The minutes of a moment

Minutes: the sixthiest part of an hour; the official record of the proceedings at a meeting; a written summary (dictionary.reference.com)

NAC: Niagara Artists Centre

Pearson: Toronto's international airport

Mississauga Schlange: Mississauga rattler, a venomous snake in Ontario

Mélusine: lady of the snakes in many European legends

Saturday 3 March 2012 was a stormy day with high winds over $104 \mathrm{~km} / \mathrm{h}$ in St. Catharines, Ont. There was not much that we could do other than having absurd conversations. This here is the detailed rendition of a conversation at the NAC about drinking snake tea (yes, snakes infusing in steamy water) and having pregnant women deliver at Pearson. All in all, a good day. 


\section{Barbara Pernar}

Mais Oui Ah !

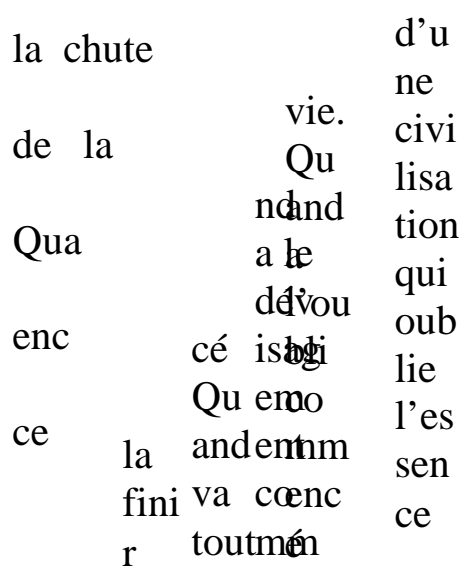

\section{co}

pulse

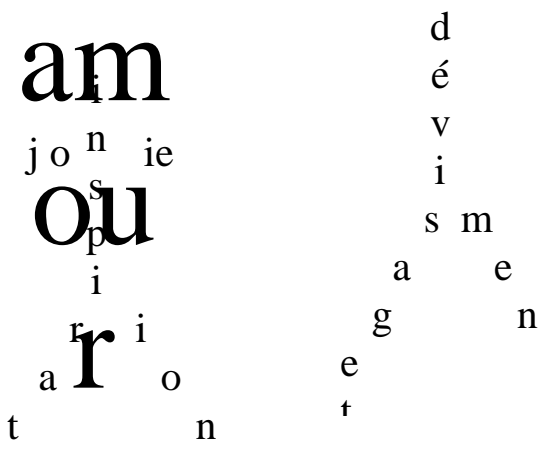

en

mé du i a
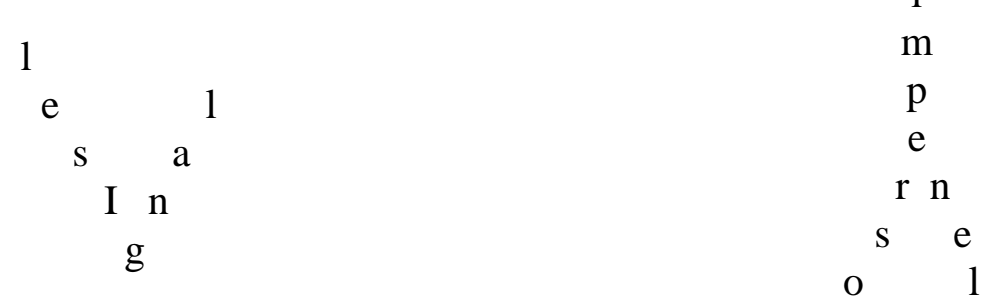

On habite tous dans ce monde

les

nôtr

es

Invi

sibl

des pensées qui ne sont pas imagi

naire

des

imag

es et 
$t i<1.1$ (Spring 2012)

\section{Jenn Garbett}

« Coche et vitrine »
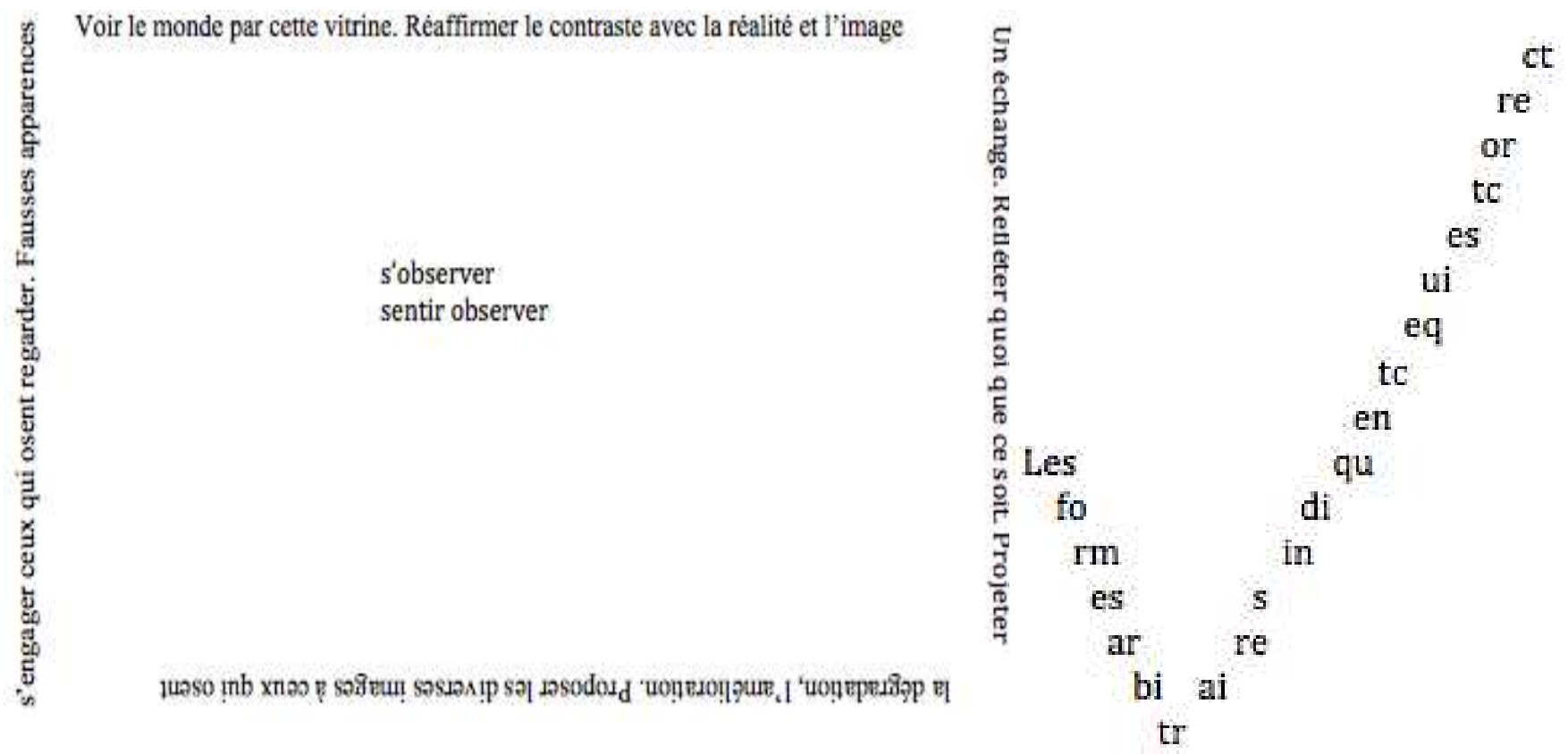

« Infinité, talon aiguille et fleur »

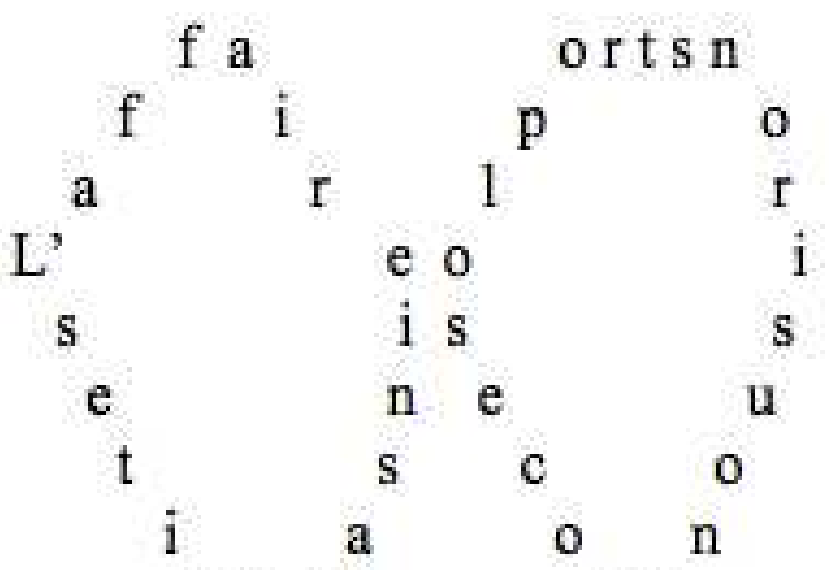

$\mathrm{m}$

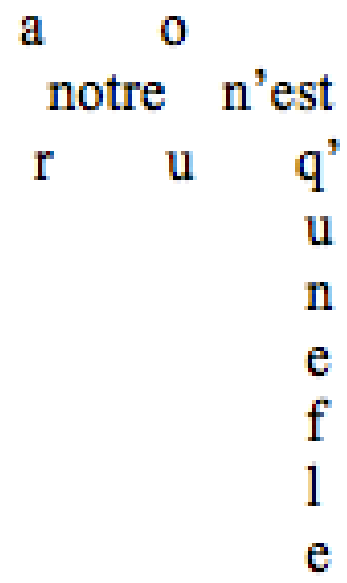

$\mathrm{milsm} \quad \mathrm{rse}$

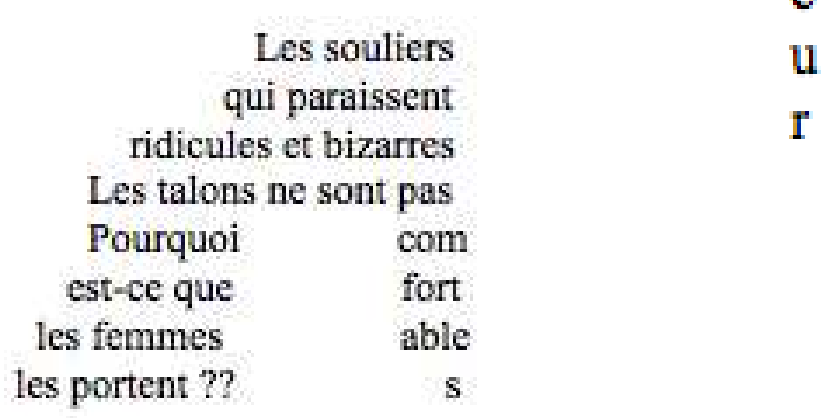


$t i<1.1$ (Spring 2012)

\section{Meagan Beaudoin}

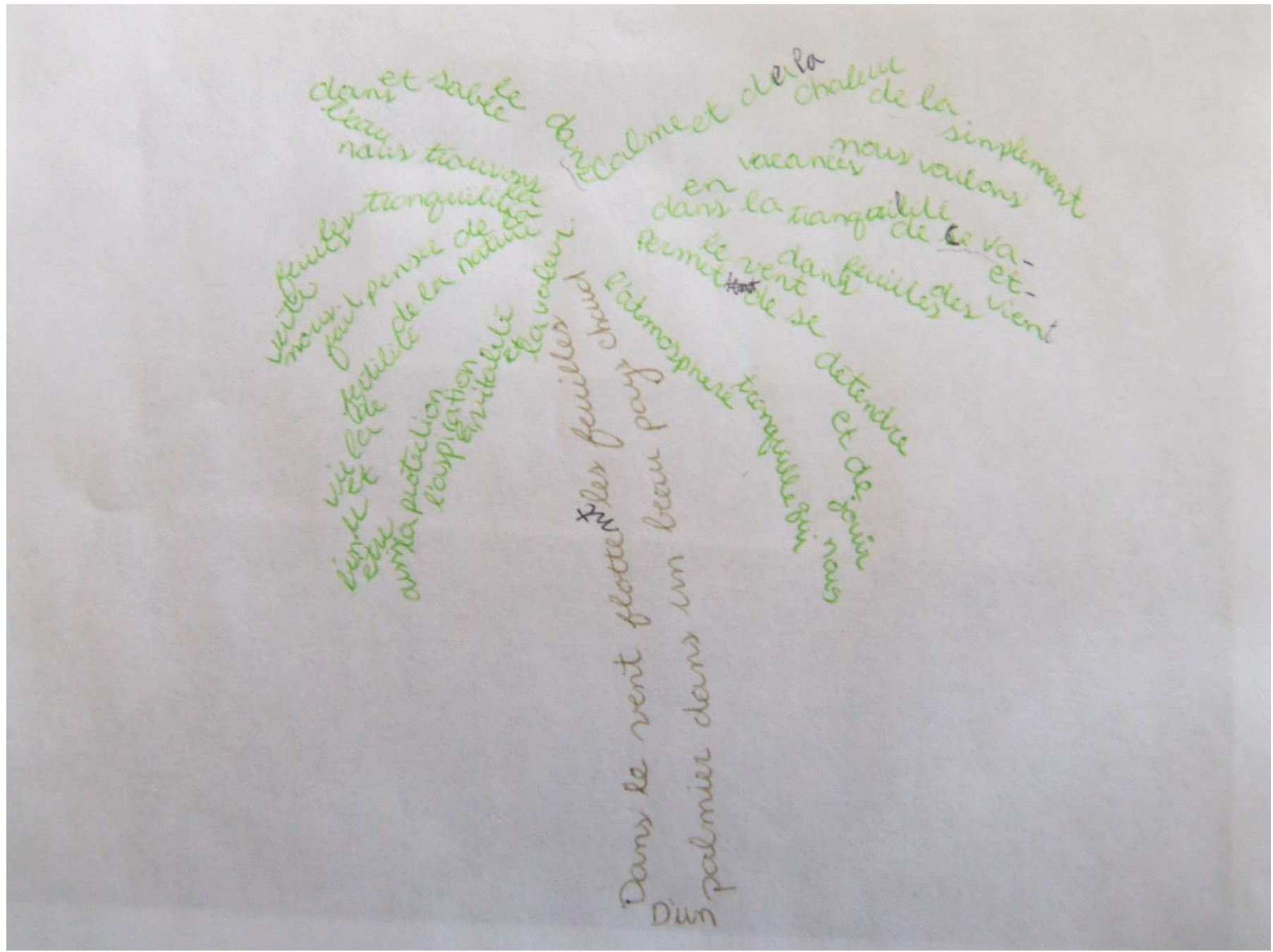




$$
10
$$


$t i<1.1$ (Spring 2012)

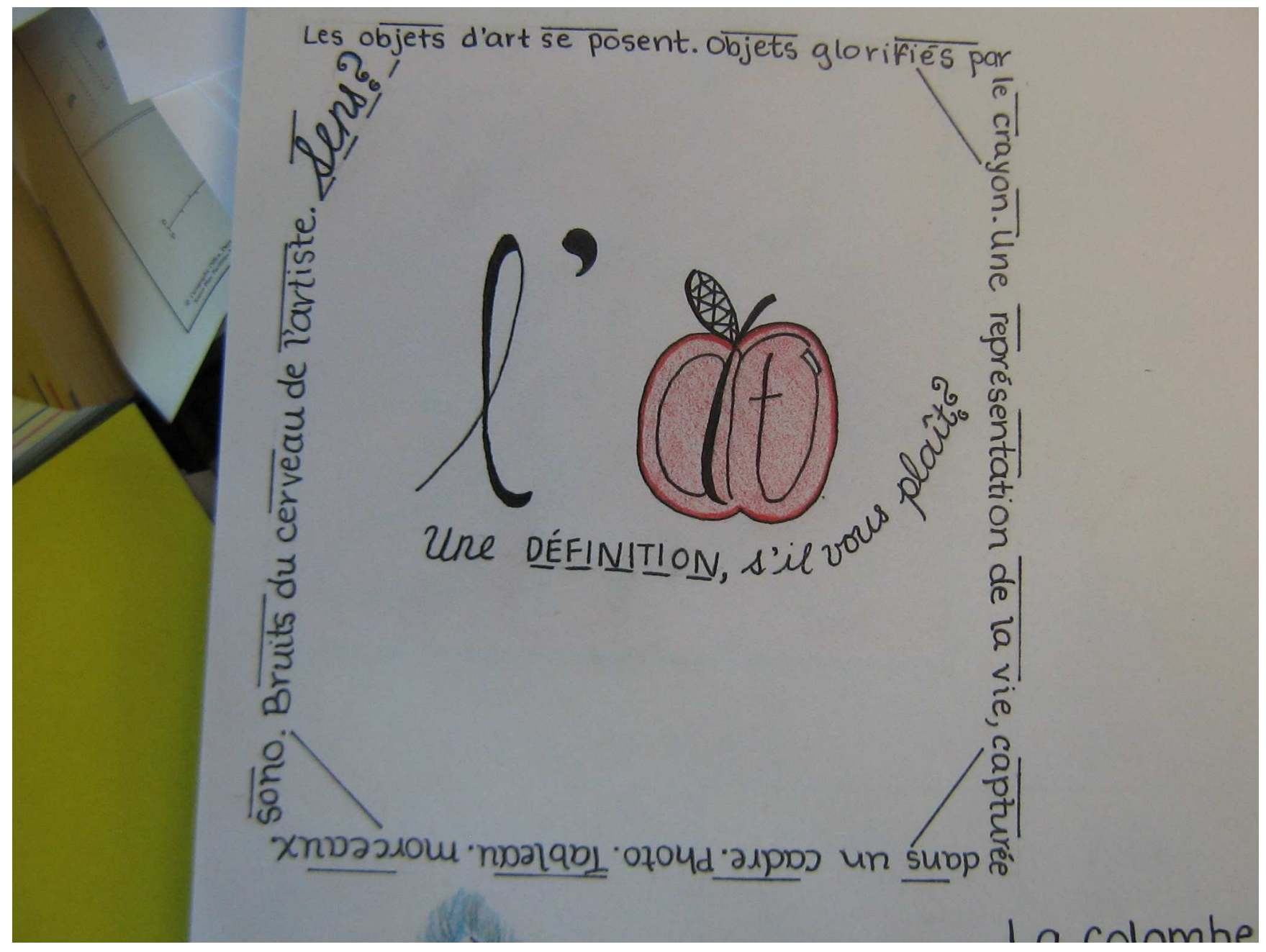


$t i<1.1$ (Spring 2012)

«La nature »

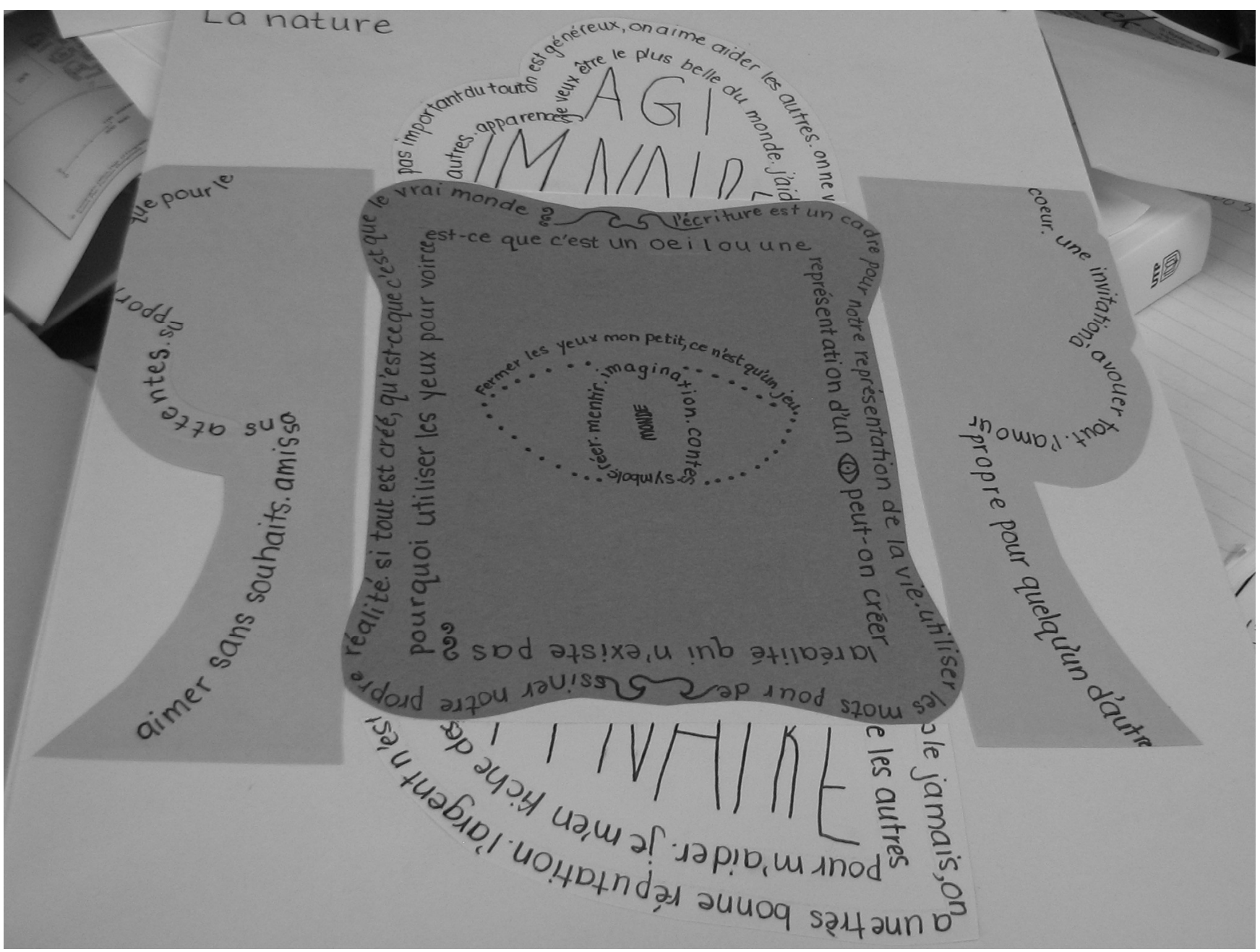


$t i<1.1$ (Spring 2012)

\section{Jacqueline Jajdelski}

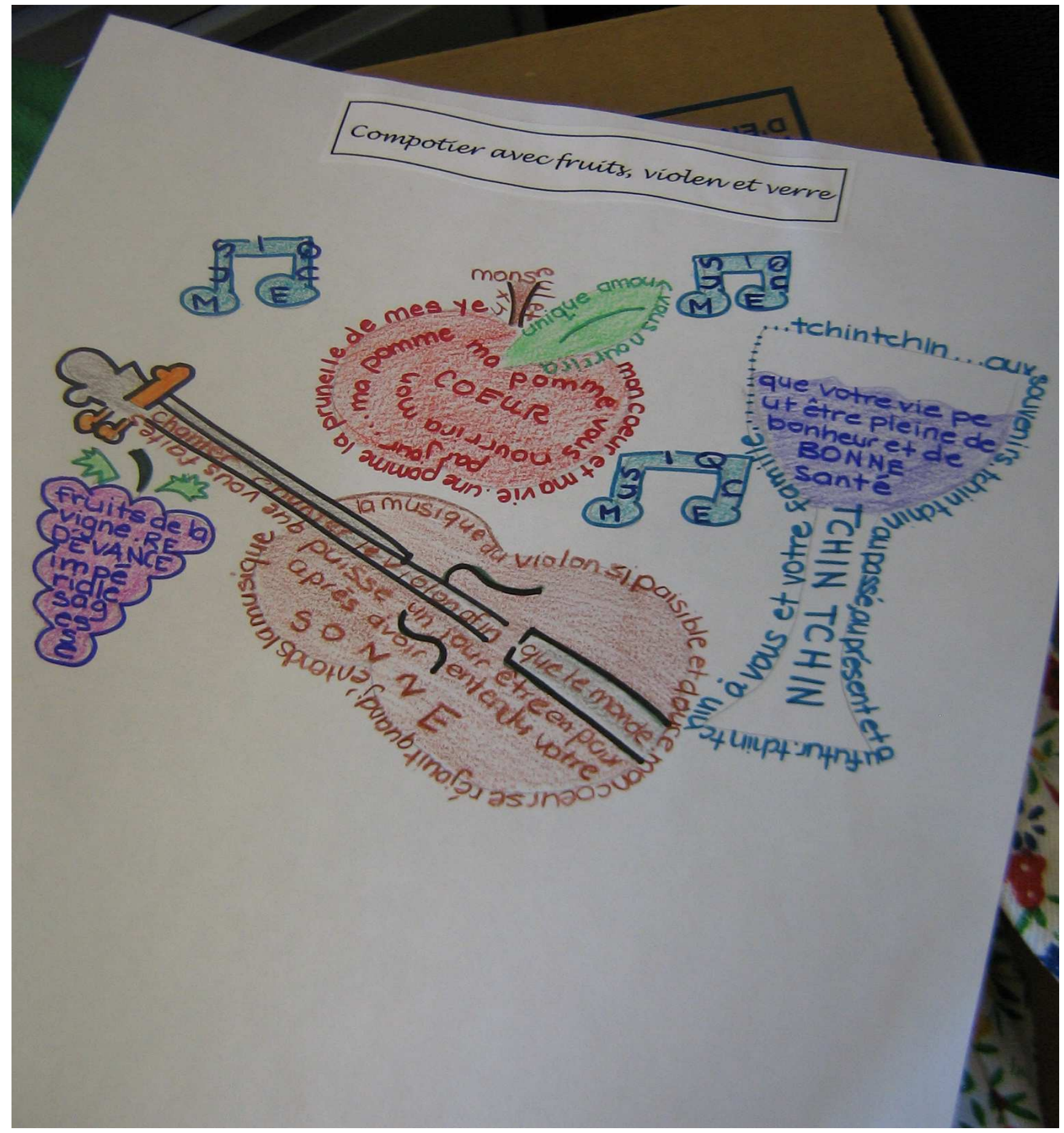


$t i<1.1$ (Spring 2012)

Melissa Nuccitelli

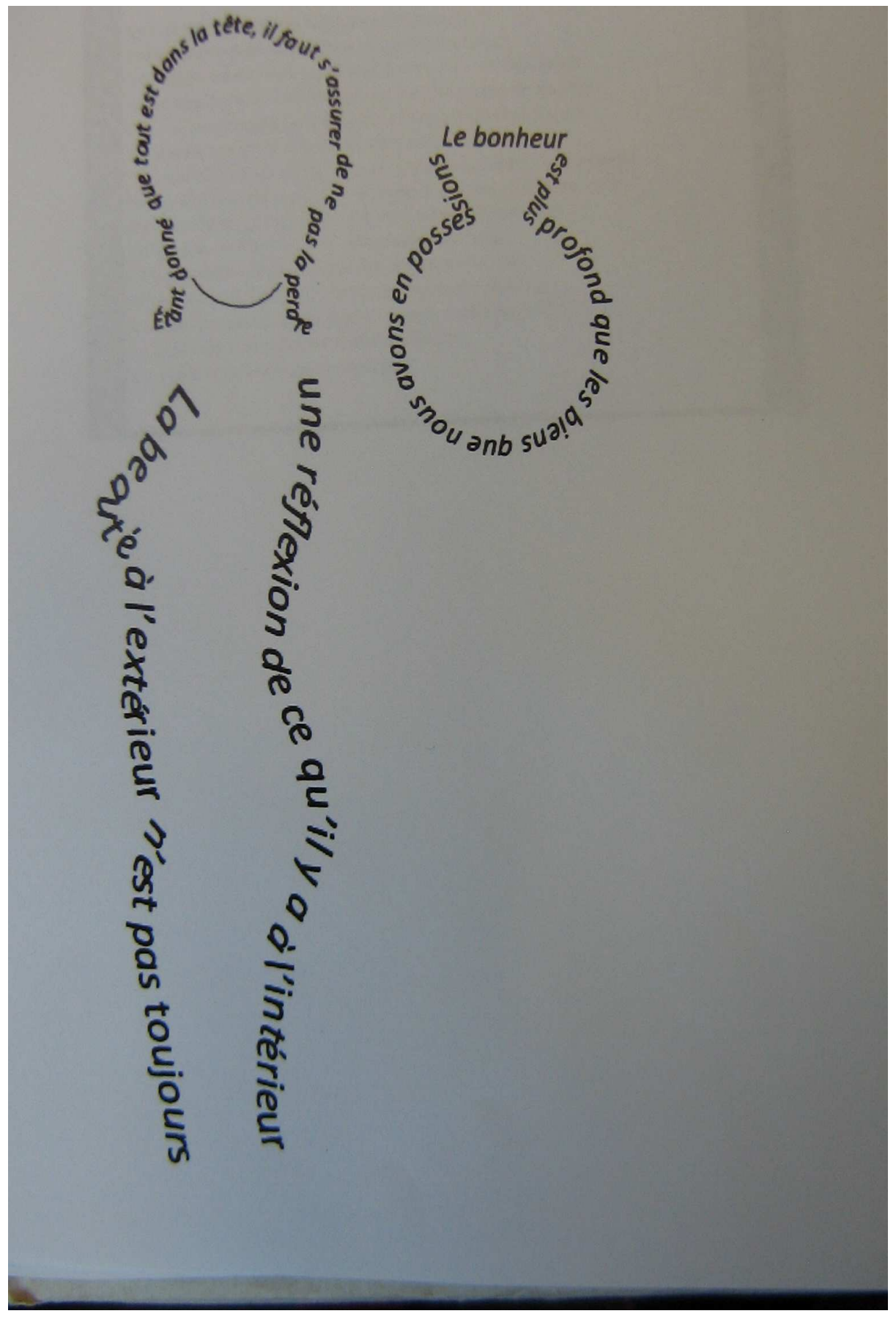




\section{Alexa Didemus}

Bougie, yeux, levres, pont en arc et tour

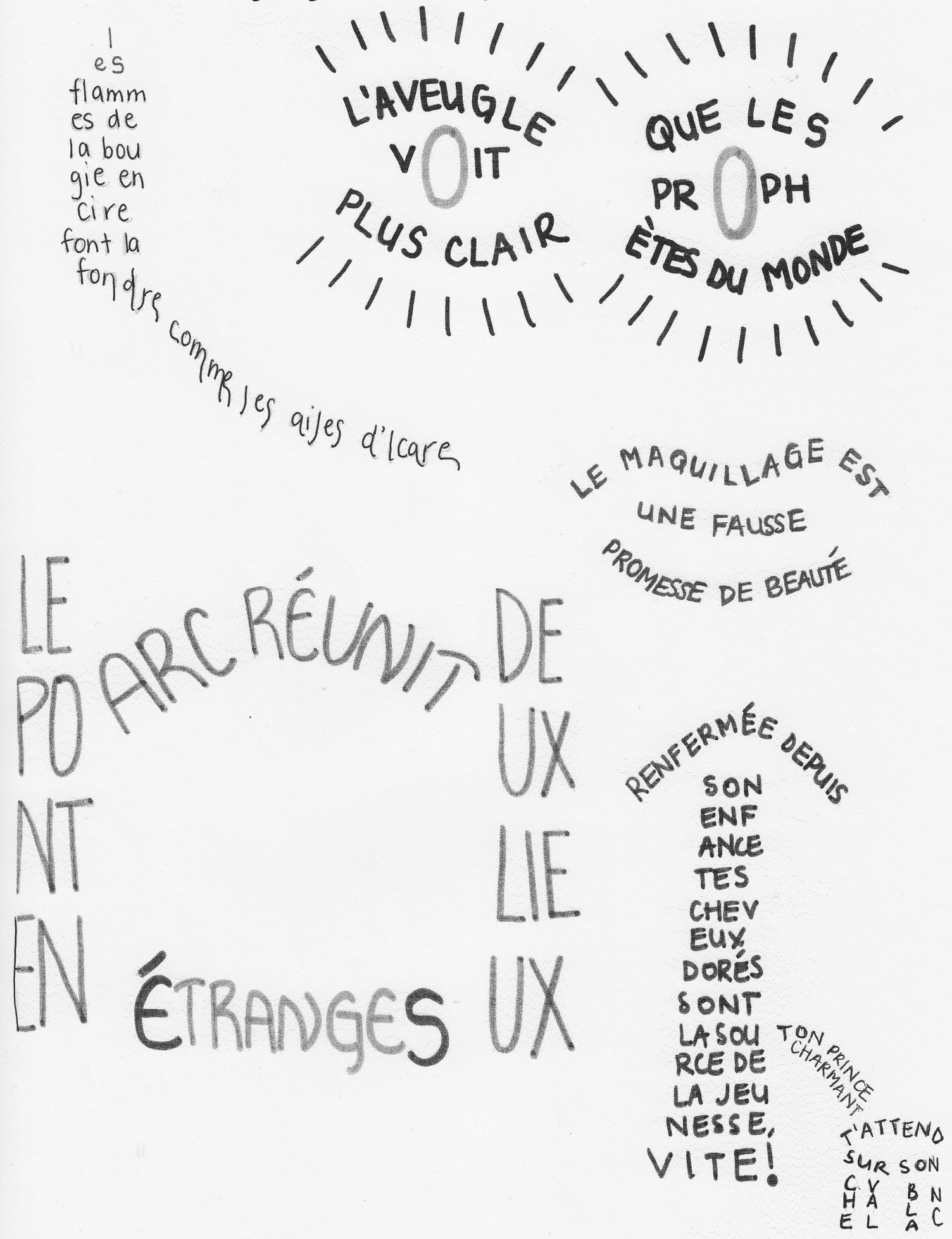




\section{Cassandra Perri}

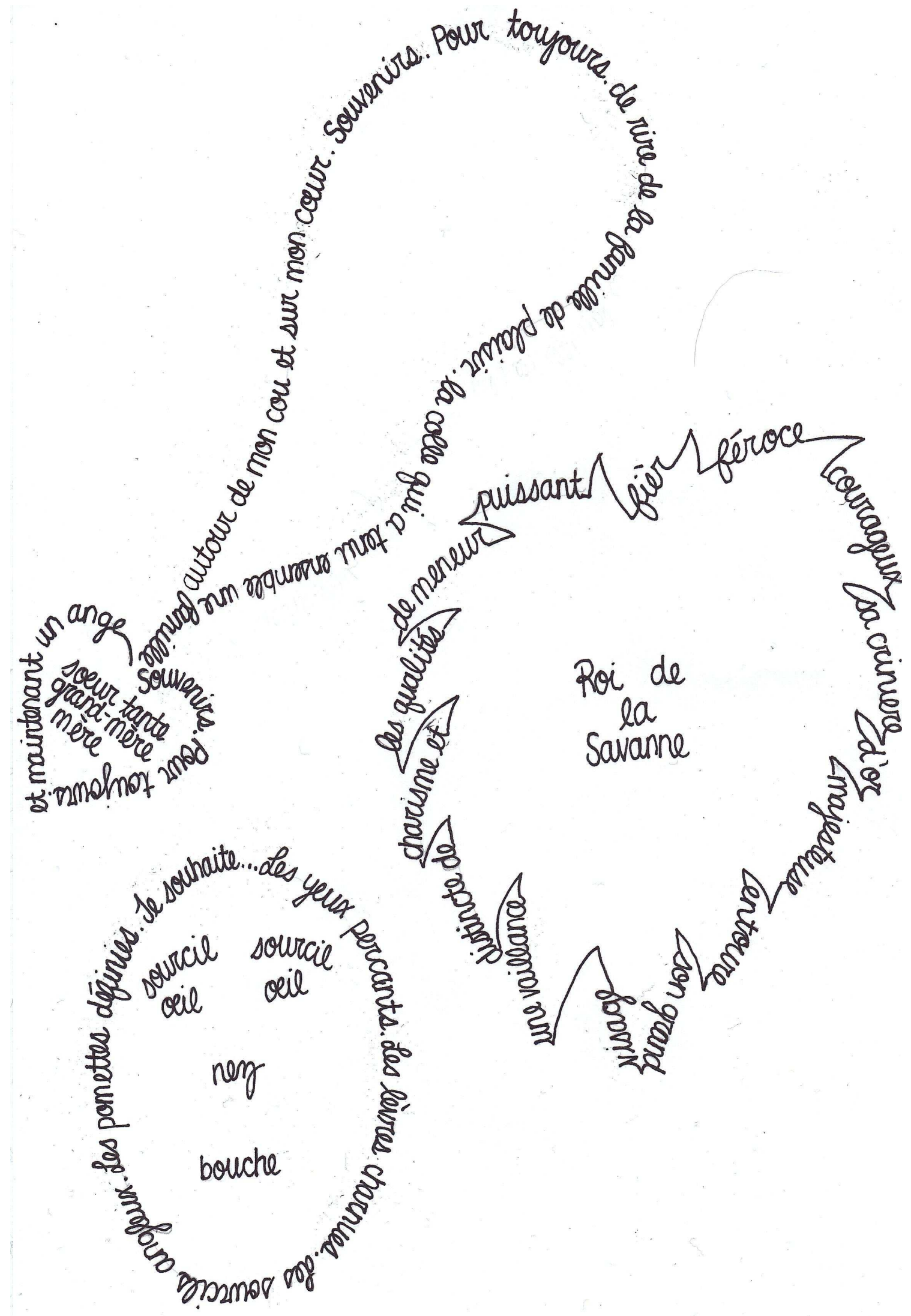




\section{Stephanie Spilkin}
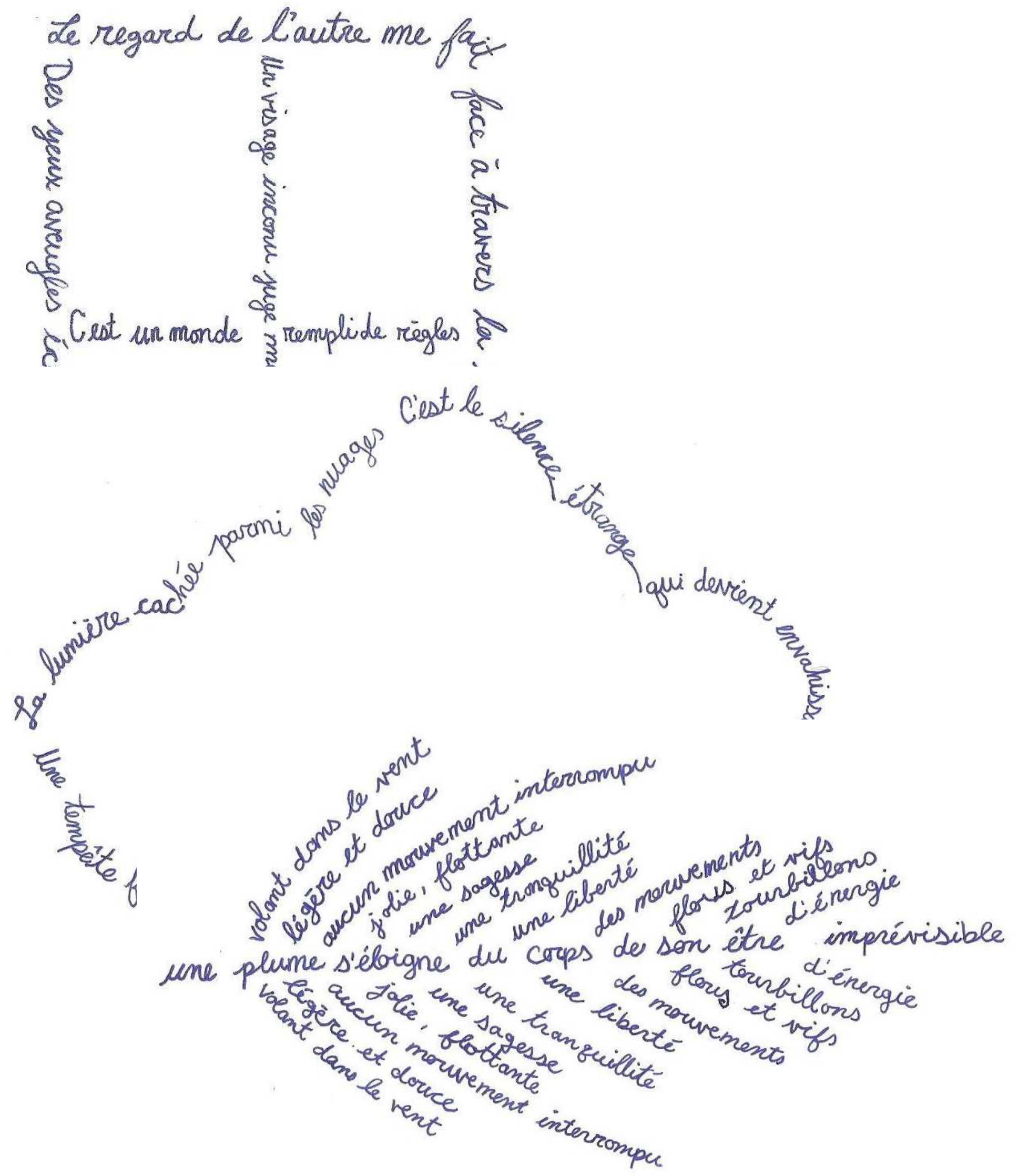
$t i<1.1$ (Spring 2012)

\section{Emily Speziale}

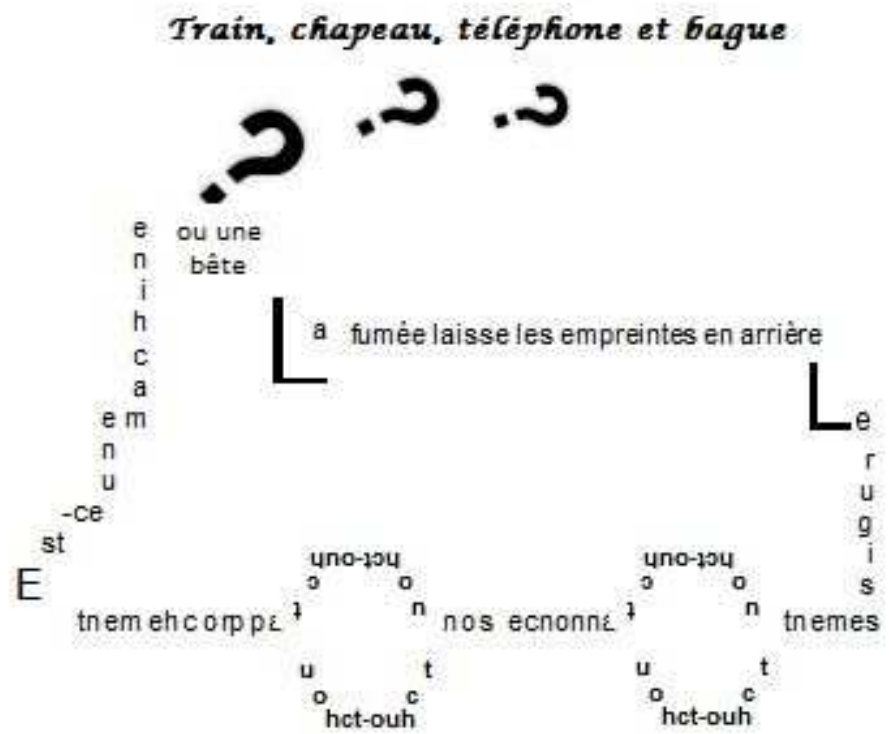

\begin{abstract}
TOUJOURS UN CHAPEAU
une étiquette sur le corps

il a l'air très beau

et on a l'air très fort

ne pas tenir compte de la

D E MANGEA I S O N

il nous protège du froid

et surtout du soleil

on ne l'enlève jamais
\end{abstract}

POUR RESTER DEGUISEE

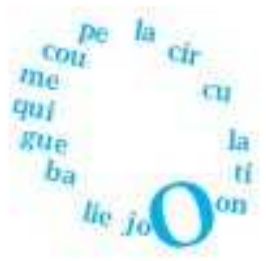

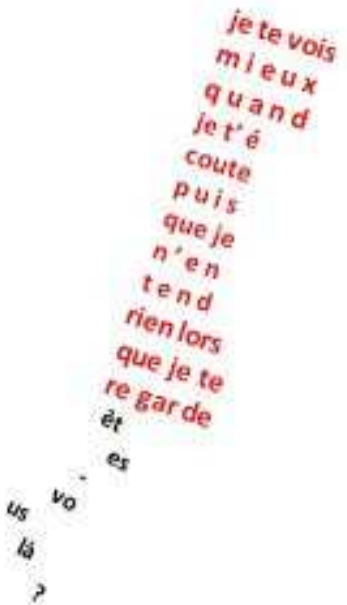

jetevois

$4 \operatorname{ann}_{0}$

coute

$\mathrm{Pu}_{\mathrm{is}}$

en

que je te

ef gar de

$4 s v_{0}$

$\rightarrow$ 